\title{
Paresia em cão por compressão da medula espinhal devido a formação de calo ósseo
}

\author{
Spinal cord compression by a periosteal callus in a dog \\ Leandro Gaiga ${ }^{1}$, Juliana Voll², Luciana Yumi Tanaka² \& Rodolfo Voll ${ }^{3}$
}

\begin{abstract}
RESUMO
A formação de calo ósseo excessivo secundário à fratura dos processos articulares vertebrais, produzindo sinais progressivos crônicos de deficiência locomotora, não é patologia comumente descrita. Este trabalho refere-se a um cão da raça Pastor Alemão, macho, quatro anos de idade atendido no Serviço de Neurologia do Hospital Clínicas Veterinárias da Faculdade de Veterinária da Universidade Federal de Rio Grande do Sul com histórico de deficiência locomotora dos membros pélvicos. O exame neurológico evidenciou paralisia do membro pélvico esquerdo e paresia leve do membro pélvico direito. O exame radiográfico demonstrou fratura e proliferação óssea dos processos articulares de T12-T13 e T13-L1. O exame mielográfico acusou compressão extradural dorsal em T13-L1. O cão foi submetido a tratamento cirúrgico utilizandose laminectomia dorsal modificada e remoção do material compressivo. A estabilização das vértebras foi feita com pinos de Steinmann e metilmetacrilato. Vinte e um dias após a cirurgia, o animal apresentou sinais de paraparesia leve com retorno da propriocepção consciente. O exame mielográfico realizado aos vinte e oito dias de pós-operatório evidenciou redução da compressão medular em aproximadamente 50\%. A melhora clínica recomenda o tratamento.
\end{abstract}

Descritores: laminectomia, cirurgia, calo ósseo.

\begin{abstract}
Formation of an exuberant periosteal callus secondary to fracture of the vertebral joint process is an uncommon cause of spinal compression in dogs. This study refers to the clinical case of a four-years-old male German shepherd dog admitted to the Neurology Service of the Veterinary Medical Teaching Hospital of the Universidade Federal do Rio Grande do Sul with paralysis of the left and a slight paresis of the right pelvic limb. Radiographic examination revealed an extradural fracture with periosteal bone proliferation of the joint processes between T12-T13 and T13-L1. Mielographic examination showed a dorsal, extradural spinal compression between T13-L1. A modified dorsal laminectomy was performed to remove the compressive tissue. Vertebral stabilization was achieved using Steinmann pins and an acrylic resin. Twenty-one days post-surgery, the patient had mild paraparesis, with presence of conscious proprioception. A new mielographic examination conducted 28 days post-surgery demonstrated a 50\% reduction in the spinal compression. Based on the clinical improvement seen in this case, we recommend surgical decompression in cases of paresis secondary to periosteal callus.
\end{abstract}

Key words: laminectomy, surgery, bridging callus.

\footnotetext{
${ }^{1}$ Serviço de Cirurgia do Hospital de Clínicas Veterinárias (HCV) - UFRGS. ${ }^{2}$ Graduação da Faculdade de Veterinária, Universidade Federal do Rio Grande do Sul (UFRGS). ${ }^{3}$ Serviço de Neurologia do HCV-UFRGS. CORRESPONDÊNCIA: J. Voll [juvoll@ibest.com.br ; Fax: +55 51 32863281 ]; Hospital de Clínicas Veterinárias - UFRGS, Av. Bento Gonçalves 9090, C.E.P. 91540-000 Porto Alegre, RS - Brasil.
} 
A compressão da medula espinhal pode ser extradural, subdural extramedular e intramedular. A compressão extradural pode estar associada a discoespondilite, espondilose, malformação vertebral, protusão discal, tumor, luxação e fratura vertebral $[1,3,7,8]$.

A causa mais comum de fraturas traumáticas é o acidente automobilístico [3]. Após a ocorrência da fratura, os fragmentos ósseos são ligados por tecidos que resistem ao movimento e que aumentam a rigidez óssea, culminando com a mineralização da fibrocartilagem, formando o calo ósseo [4,6]. A quantidade de calo formado depende diretamente do grau de movimento dos fragmentos, pois quanto maior a instabilidade, maior será o diâmetro do calo [2,5].

O tratamento da compressão da medula espinhal deve aliviar a pressão sobre a medula espinhal e restabeler a perfusão vascular. Tais objetivos podem ser alcançados através da criação de espaço adicional para medula espinhal e da remoção de massa compressiva $[3,7,8]$.

A laminectomia dorsal é indicada para remoção de massas compressivas nas faces ventrolaterais e dorsal do canal espinhal e, devido à instabilidade secundária decorrente, recomenda-se associá-la a alguma técnica de estabilização [3].

Existem diversos métodos para estabilização da coluna vertebral, sendo que a fixação dos corpos vertebrais utilizando pinos de Steinmann e cimento ósseo proporciona um excelente meio rígido de estabilização espinhal $[1,3,7]$.

Em razão da escassez de dados na literatura, o presente trabalho tem como objetivo descrever um caso de paresia em um cão ocasionada por compressão da medula espinhal devido a processo reacional resultante de fratura óssea.

\section{CASO CLÍNICO}

Foi atendido no Setor de Neurologia do Hospital Clínicas Veterinárias da Faculdade de Veterinária da Universidade Federal de Rio Grande do Sul um cão Pastor Alemão, macho, quatro anos, com deficiência locomotora dos membros pélvicos. O exame neurológico evidenciou paralisia do membro pélvico esquerdo e paresia leve do membro pélvico direito. $\mathrm{O}$ exame radiográfico demonstrou fratura e dos processos articulares de T12-T13 e T13-L1 (Figura 1). O exame mielográfico acusou compressão extradural dorsal em
T13-L1 (Figura 2). Foi realizada abordagem cirúrgica às vértebras através de incisão na linha média dorsal, secção da gordura e fáscia subcutâneas, incisão do ligamento supraespinhal e divulsão da musculatura até visualização dos processos articulares alterados (Figura 3). Posteriormente, foi feita remoção total dos processos espinhosos dorsais de T13 e L1, assim como remoção total dos processos articulares caudais de T13; quanto aos processos articulares craniais de L1, houve remoção parcial. Foram removidas as corticais ósseas externas e internas, até exposição da medula espinhal. A estabilização das vértebras foi feita através de inserção de dois pinos de Steinmann de 2,5mm nos corpos vertebrais de T13-L1 em ângulo aproximado de 30 graus (Figura 4), sendo logo depois de fixados com metilmetacrilato (Figura 5). Utilizou-se para rafia da fáscia muscular e redução do espaço morto fio de poliglactina 910 n $^{\circ}$ 3-0 em padrão de sutura contínua simples e para pele fio de mononáilon $\mathrm{n}^{\circ} 3-0 \mathrm{em}$ padrão de sutura isolado simples. O material removido foi enviado para exame histológico.

Vinte e um dias após a cirurgia o animal apresentou sinais de paraparesia leve com retorno da propriocepção consciente. $\mathrm{O}$ exame mielográfico realizado aos vinte e oito dias de pós-operatório evidenciou redução da compressão medular em aproximadamente $50 \%$ (Figura 6). Ao exame histológico foi observada presença de cartilagem hialina e osso trabecular trançado.

\section{DISCUSSÃO E CONCLUSÕES}

Neste caso, a compressão da medula espinhal foi feita por processo reacional (calo ósseo) secundário a fratura, conforme demonstraram os exames radiográfico e histológico. A lesão óssea inicial, apesar de não relatado na história, foi atribuída a trauma externo como causa das fraturas dos processos articulares. A ausência de tratamento gerou certo grau de instabilidade crônica que determinou a formação de calo ósseo excessivo com compressão gradual da medula espinhal.

A descompressão produzida pela laminectomia dorsal modificada associada à estabilização com pinos de Steinmann e metilmetacrilato foi eficiente como forma de tratamento, o que ficou evidente pela redução da gravidade dos sinais neurológicos, justificando a opção pela intervenção cirúrgica em processos patológicos dessa natureza. 


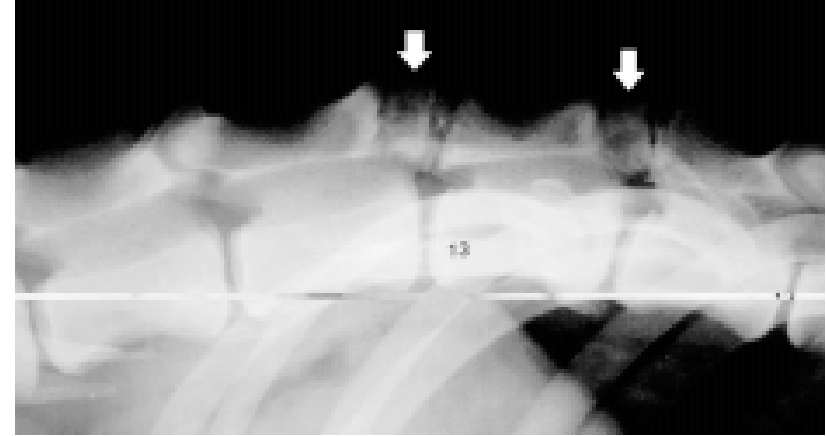

Figura 1. Exame radiográfico pré-operatório, onde se observa fratura e proliferação óssea dos processos articulares de T12-T13 e T13-L1 (setas).

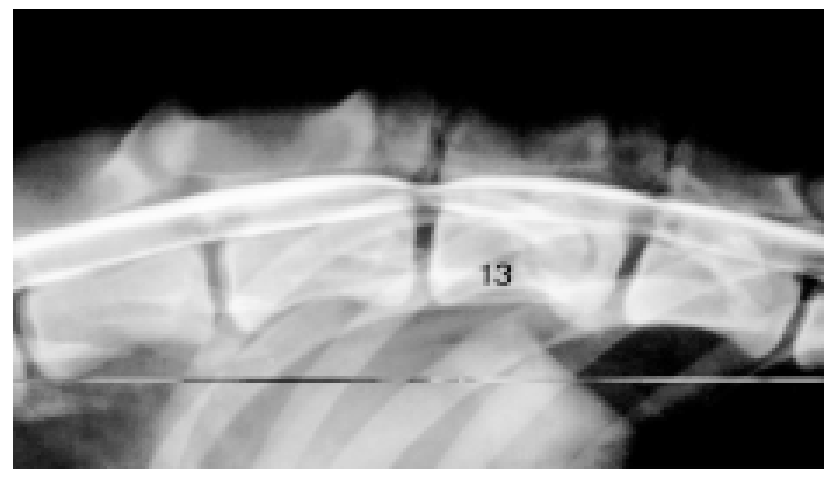

Figura 2. Exame mielográfico pré-operatório demonstrando compressão medular T13-L1.

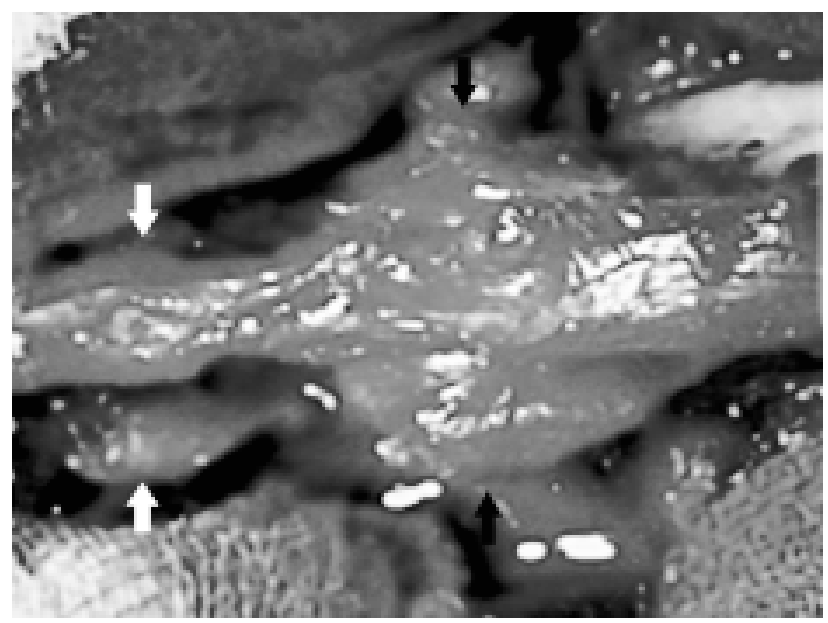

Figura 3. Abordagem dorsal à coluna toracolombar com visualização dos processos articulares T12 e T13 normais (setas brancas) e T13 e L1 aumentados (setas pretas).

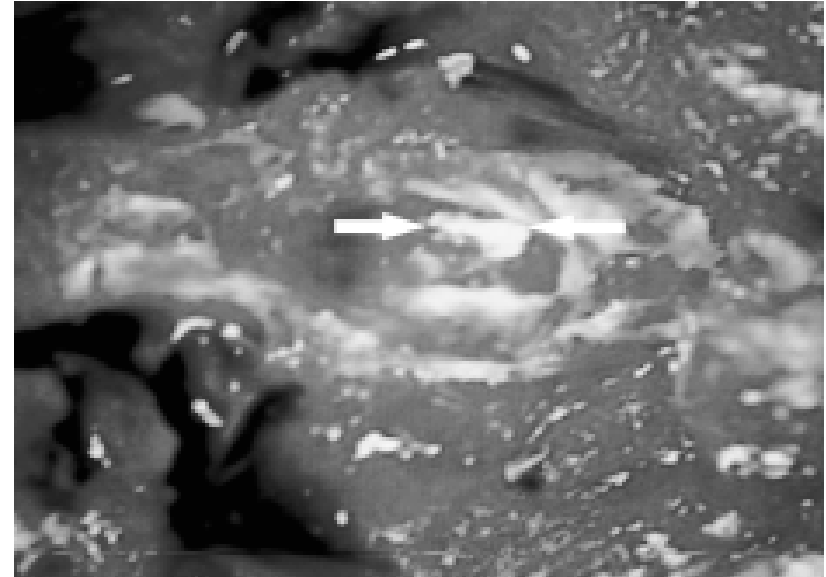

Figura 4. Laminectomia dorsal modificada com exposição da medula espinhal (setas). Observar a inserção em ângulo dos pinos de Steinmann nos corpos vertebrais de T13-L1.

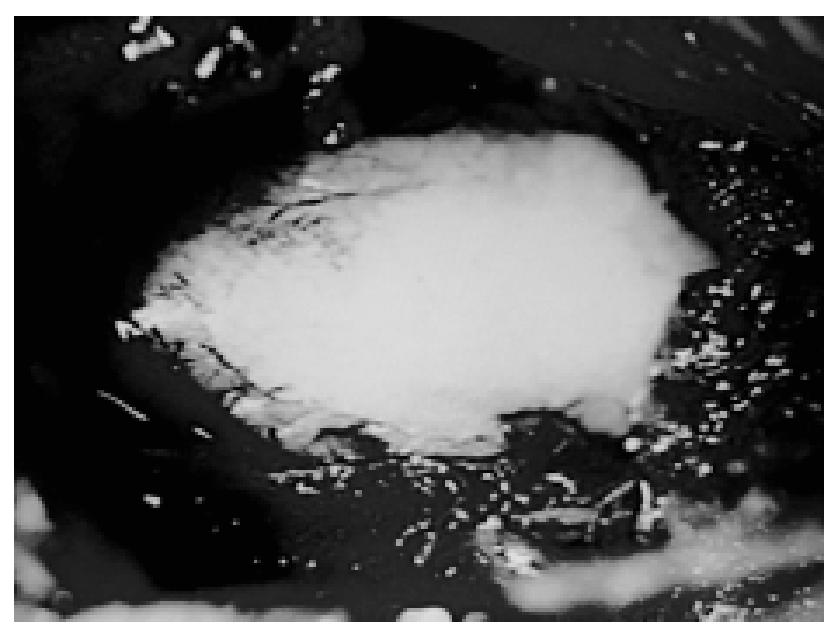

Figura 5. Colocação do metilmetacrilato sobre os pinos.

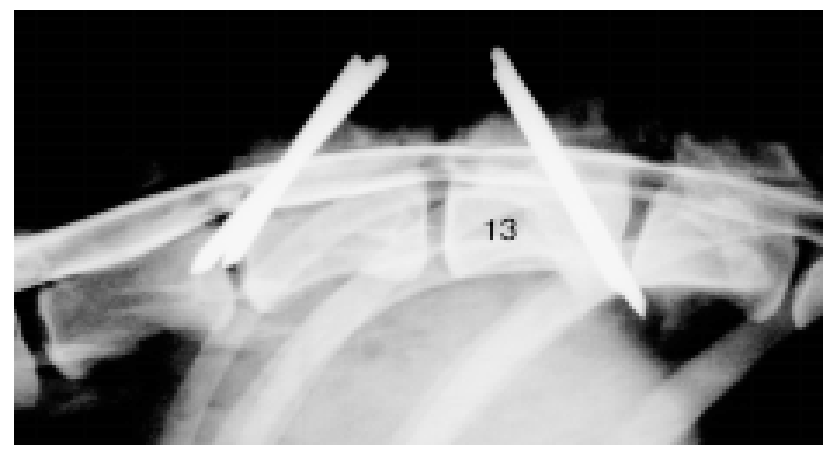

Figura 6. Exame mielográfico realizado aos 28 dias de pósoperatório, onde se observa redução da compressão medular.

\section{REFERÊNCIAS}

1 Blass C.E. \& Seim H.B. 1984. Spinal fixation in dogs using Steinmann pins and methylmethacrylate. Veterinary Surgery. 13: 203-210.

2 DeYoung D.J. \& Probst C. 1998. Métodos de Fixação de Fraturas - Princípios Gerais. In: Slatter D. (Ed). Manual de Cirurgia de Pequenos Animais. São Paulo: Manole, pp. 1909-1932. 
3 Fossum T.W. 2002. Cirurgia da Espinha Toracolombar. In: Cirurgia de Pequenos Animais. São Paulo: Roca, pp. 12161246.

4 Fossum T.W. 2002. Fundamentos da Cirurgia Ortopédica e Tratamento de Fraturas In: Cirurgia de Pequenos Animais. São Paulo: Roca, pp. 786-853.

5 Hulse D. \& Hyman B. 1998. Biologia e Biomecânica das Fraturas. In: Slatter D. (Ed). Manual de Cirurgia de Pequenos Animais. São Paulo: Manole, pp. 1891-1901.

6 Piermattei D.L. \& Flo G.L. 1997. Handbook of Small Animal Orthopedics and Fracture Repair. 3rd edn. Philadelphia: W.B. Saunders Company, 743p.

7 Seim III H.B. \& Bruecker A.K. 1998. Fraturas e Luxações Vertebrais. In: Slatter D. (Ed). Manual de Cirurgia de Pequenos Animais. São Paulo: Manole, pp. 1332-1344.

8 Vandelvelde M. \& Wolf M. 1998. Compressão da medula espinal In: Bojrab M. J. (Ed). Mecanismo da Moléstia na Cirurgia. 3.ed. São Paulo: Roca, pp. 1326-1332.

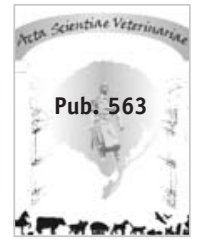

